MEDICO RESEARCH CHRONICLES

ISSN NO. 2394-3971

DOI No. 10.26838/MEDRECH.2021.8.3.491

Contents available at www.medrech.com

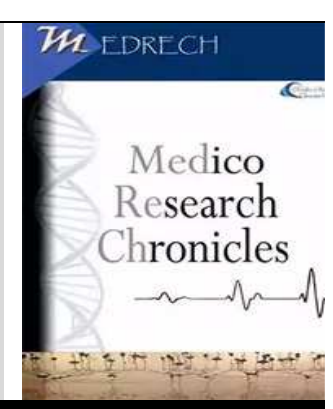

\title{
CLIMATE CHANGE: - A POTENTIAL RISK FACTOR FOR CANCER?
}

Pallab Chakraborty ${ }^{*}$

Post graduate student; B. Sc in Zoology; University of Calcutta, India

ARTICLE INFO

Article History

Received: April 2021

Accepted: May 2021

Keywords: Climate

change, Health impacts,

Skin Cancer, Lung

cancer, Awareness

Corresponding author*

Pallab Chakraborty
SHORT COMMUNICATION

Cancer, mainly known for abnormal growth and altered cellular function is now the second prominent reason of death in the world. There are so many factors responsible for this disease and one of the major factors is climate change. The deviations of weather patterns that is definitely as a result of human activities over long periods of times generally referred as climate change. The consequences include, increasing temperature, melting of ice, rising of sea levels, increasing wind speed, changes in rainfall patterns etc. Due to all these concerns, the most important resource for a healthy life- Air, Water, and Food are gets disturbed and as a results causes several health-related problems. Previous researches related to this field also demonstrated that climate change played critical role over cancer risk and cancer surveillance. It increases the amount of carcinogens and also its blocks patients' access to cancer hospitality. Here in this article you will get to know about the impacts of climate changes on health. Why this can be potential risk factors for cancer by focusing mainly on lung and skin cancer and about some well-known limitations that we need have to resolve in the near future. In this concerns several steps has been implicated globally but more preparedness and attentiveness are reasonable.

O2021, www.medrech.com

\section{INTRODUCTION:}

It is well known to us that climate change has very unique impacts on health but unfortunately it is dangerous ${ }^{1}$. Mostly due to human activities, the normal patterns of weather get changed dramatically and the consequences, like high temperature, rainfall, melting of ice, rising of sea levels, increasing of wind speeds all these disrupting the healthcare, social, economic structure globally $^{1,2}$. Data published in 2008 indicates that the burning of fossil fuels, deforestation by humans helps to increase carbon dioxide up to $30 \%$ that traps heat into the atmosphere causing rising in temperature ${ }^{3}$. The report from AR4 IPCC 2007 also says that at 21 century ends, worldwide peoples will experience a higher temperature than the last 10,000 years because the surface temperature will vary between 1.1 and 6.4 degrees Celsius and the sea level will rise estimated $0.17 \mathrm{~m}$ during the $20^{\text {th }}$ century ${ }^{3}$. Recent data supports its role in 
several health-related disorders like vectorand water-borne diseases, lung disease, skin problems, and also cancer ${ }^{2,4,5}$. Still, now the fact is that it is not fully curable but on the other, the number of carcinogens in nature is getting increased by the effect of climate change ${ }^{6}$. It also found to be acts as a barrier for cancer patients to access cancer care, treatments, and hospitality thus impacting survivals ${ }^{7}$. The major drawback is that majority of the people are not educated or warned in this case that again proved by the small recent survey (see in point number 5). So for all these everyone should be aware of its bad effects and try to heal our beautiful nature. In this concern more caring and more effective warranted from both nations and every individual. This abstract was accepted at the 2020 GW4 Symposium Climate Change Science \& Society and I have presented my topic on $3^{\text {rd }}$ December 2020. Here in this article, I have summarized the role of climate changes over health and cancer in brief.

\section{METHODS:}

For this manuscript, I did a literature review from Google Scholar, Research Gate, and
Google search engine. I have used climate change, cancer as the major search keywords. Here a survey data also presented. I did the online survey for one week long through the Google forms (Received response, $\mathrm{N}=31$ ) and the main focus of this survey was to get an instant idea about how much aware people of climate change and cancer.

\section{THE RELATION WITH HEALTH:}

Climate change has a very important role in healthcare. It can become from several dimensions and directly or indirectly can affect human health. Here in brief I have summarized the relationship between climate change and health problems. Like heat waves that are linked with climate change and cause the highest deaths mostly suffer the Western European peoples ${ }^{1,8}$. Elderly peoples have died in this as it can contribute to several cardiac and respiratory problems as high temperature found to increase the heart rate so can cause heart attack and failure on the other the high temperature can contribute to multi-system failure ${ }^{9}$. Climate change can also increase air pollution too and impacts health ${ }^{1}$. Natural disasters like floods, droughts also performed a key role in human health ${ }^{10}$.

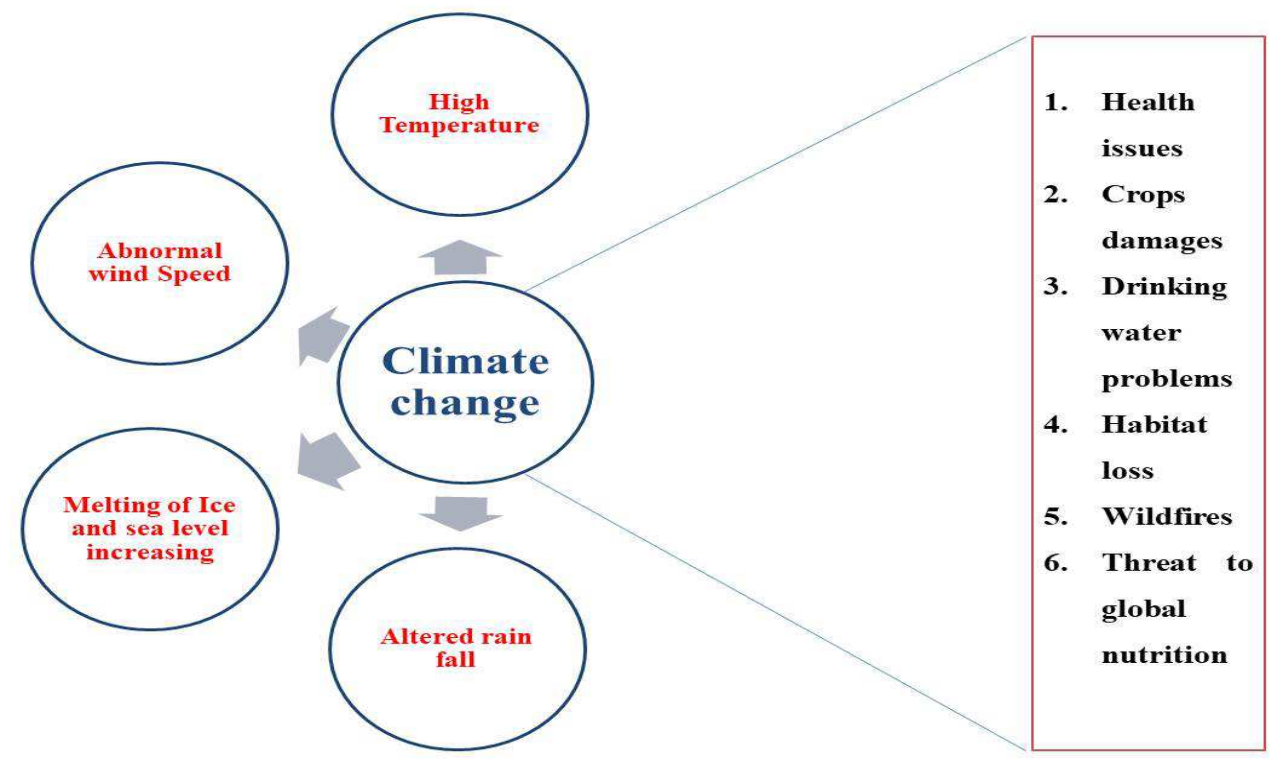

Fig.1: Schematics represents climate change and its effects. 
Floods can be the reason for the mobility of toxic chemicals ${ }^{11}$, it cause diarrheal and respiratory diseases ${ }^{1,10}$ both high- and lowincome countries, Droughts and floods both together can hinder several important facilities like hospitals, electricity, drinking water, 12 crops, etc., and by all these means it contributes towards human's health. The vector-borne infectious disease also gets affected using their transmission procedure with climate change, as associated to humidity, heat, altered rain, etc., and contributed to our health ${ }^{13}$. A brief overview of this is demonstrated in figure 1.

\section{RELATION WITH CANCER:}

As discussed, changing weather causes several health problems it also reported to contribute to cancer. Previous articles published in this field also support that it can contribute also to cancer through increasing carcinogens ${ }^{6}$ and one of them is dioxin with 50 years half-life ${ }^{7,14}$. The wildfires that have a great role in air pollution also contribute to cancer by increasing the particulate matter in the environment ${ }^{15,16}$.

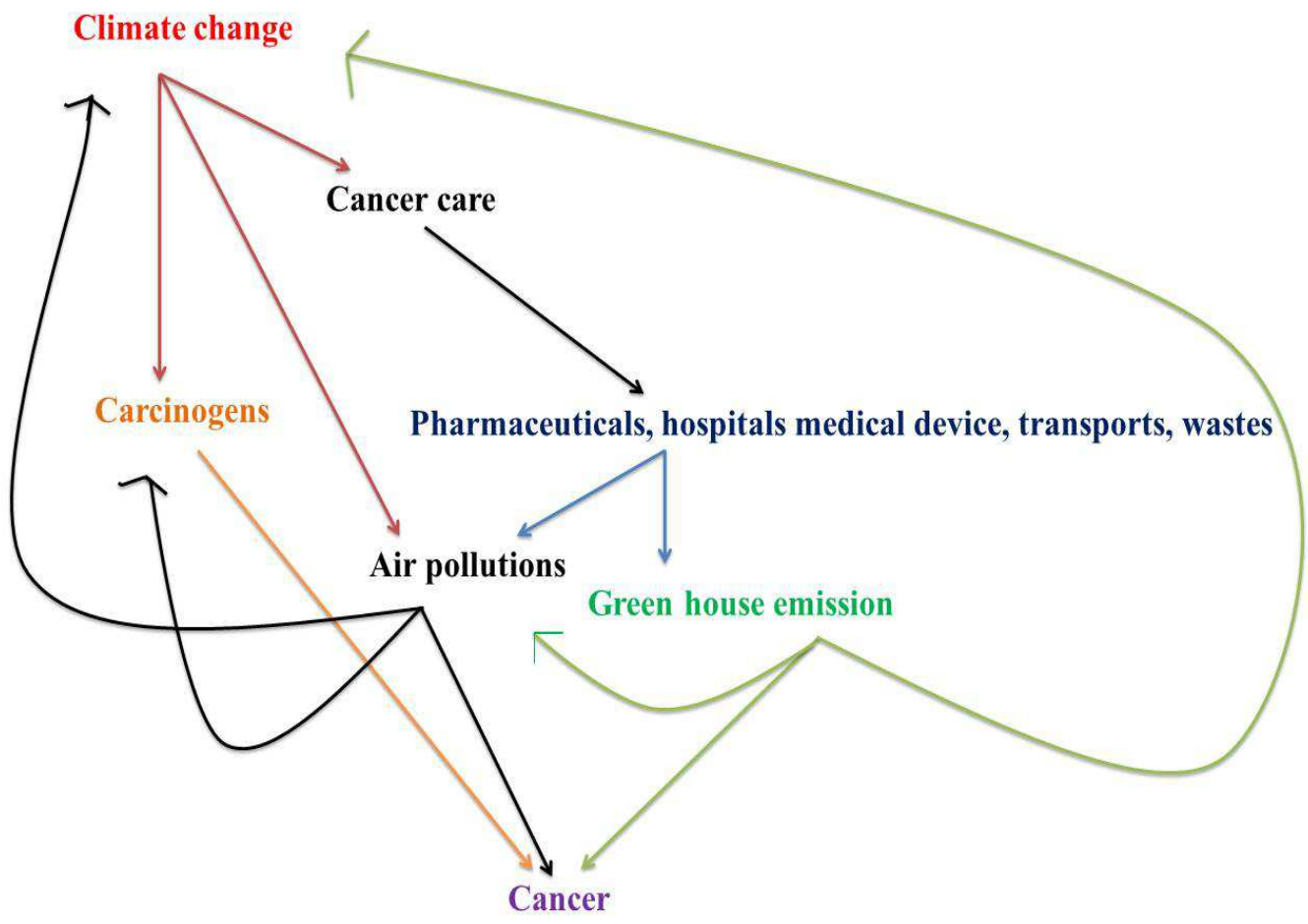

Fig.2: Climate change and cancer relation

Weather changes also can uphold the concentration of aflatoxin, a potent carcinogen in dietary sources ${ }^{17}$. According to the reported data, changes in environment like high temperature can increase the concentration of aflatoxin of Aspergillus sp and lower in clod season ${ }^{18}$. There are mainly 3 types of known skin cancers, Basal cell carcinoma(BCC) Squamous cell carcinoma(SCC), and malignant melanoma(MM) and among these most dangerous is malignant melanoma due to death up to $80 \%{ }^{5}$. It is reported that weather changes and their adverse effects like heat, ozone depletion by chlorofluorocarbons, and sun exposer, ultraviolet exposers all can contribute to skin cancer development ${ }^{4,5,19,20}$. The direct exposer of the sun in child hood and adolescence can promote $\mathrm{BCC}{ }^{21}$, in case of $\mathrm{SCC}$, the guardian of the genome gets mutated by UV exposer and helps the development of 
these types of tumors ${ }^{22}$ and MM also formed due to UV-B and UV- A 5 . Apart from the particulate matters, volatile organic compounds (VOCs), ozone, nitrogen dioxide, and Sulphur dioxide also contribute in skin cancer ${ }^{23}$, specifically the PM and polycyclic aromatic hydrocarbons impacts majorly in skin cancer experimented in animal models ${ }^{24}$.

The adverse effects of climate change also responsible for lung cancer development 25. It's mostly affected by air pollution due to biomass combustion or coal gas ${ }^{25,26}$. Not only lung cancer other respiratory diseases like COPD(Chronic obstructive pulmonary disease) are also caused by indoor pollution ${ }^{27-}$ 29 . It was measured that apart from tobacco smoking the indoor pollution (wood fire, fire generated from waste or coal) are highly dangerous for the lung cancer especially for the women who are using coal for cooking purpose ${ }^{25}$. The lung cancer formation rate incidents in women are found 3 fold higher from the past 20 years and according to smoking history, it is $50 \%$ higher in men than before 20 years ${ }^{30}$. According to WHO (world health organization) the 3 billion peoples are cook using the normal stove with kerosene or wood or other waste or coal and,3.8 million peoples are died due to this indoor pollution, and $8 \%$ of them are died due to lung cancer ${ }^{31}$, that tells us about its severity itself. In this concern in India Prime Minister Shri Narendra Modi led the central government launched LPG scheme known as Pradhan Mantri Ujjwala Yojana ${ }^{32}$, that is a very effective step, as the main objective is to save rural woman's mainly of India from health hazards that come from fossil fuels and it could reduce household air pollution too.

Here the notable point is that the consequences of climate change not only cause cancer by increasing carcinogens only, one another major problems is related to cancer care because it disrupts healthcare facilities and delivery that is the most important for the treatment, diagnosis of cancer patients ${ }^{33}$. Due to hurricanes most of the cancer patients ( Non-small cell lung cancer) are dying due to the disruption of radiation therapy according to Nogueira LM et $a l$ research ${ }^{34}$ and specifically, hurricane Maria in 2018 causes a national shortage of intravenous medicine ${ }^{35}$. The healthcare system mainly the pharmaceutical industries and hospitals are also released several gases like anesthetic gas used in surgery which is more dangerous than carbon dioxide, and this is the source of carbon footprint 7,36,37. The energy costs in cancer treatment facilities, medication, from packaging to delivery of the pharmaceuticals, considerably impacts greenhouse gas discharges ${ }^{7}$. The transport of patients and staff to specialized cancer treatment indirectly contributed to vehicle emissions that promote climate change, although it can be minimized by promoting physical means like walking, cycling, etc. ${ }^{38,39}$.

All the information in this field has proved that climate change is very important related to the development of cancer, so we can say that this climate change is a potential risk factor for cancer, and in the present situation, everybody should have to be concerned with its side effects.

\section{SURVEY RESULTS:}

For knowing the people's awareness about climate change and its impact on cancer I have performed a 7 days long online survey and the data is very impressive as presented below from fig 3-6. According to the result, the peoples from the age group of 18 to $>31$, $90.3 \%$ of them are very concerned about climate change and its impact on health but $9.7 \%$ are not. Another response from the same age group also indicates that about $12.9 \%$ of total participants are not sure whether the weather change can contribute to cancer or not. Data represented here from only 31 responses, and it is based on India thus more responses are required globally for proper evaluation. The data are represented below. 


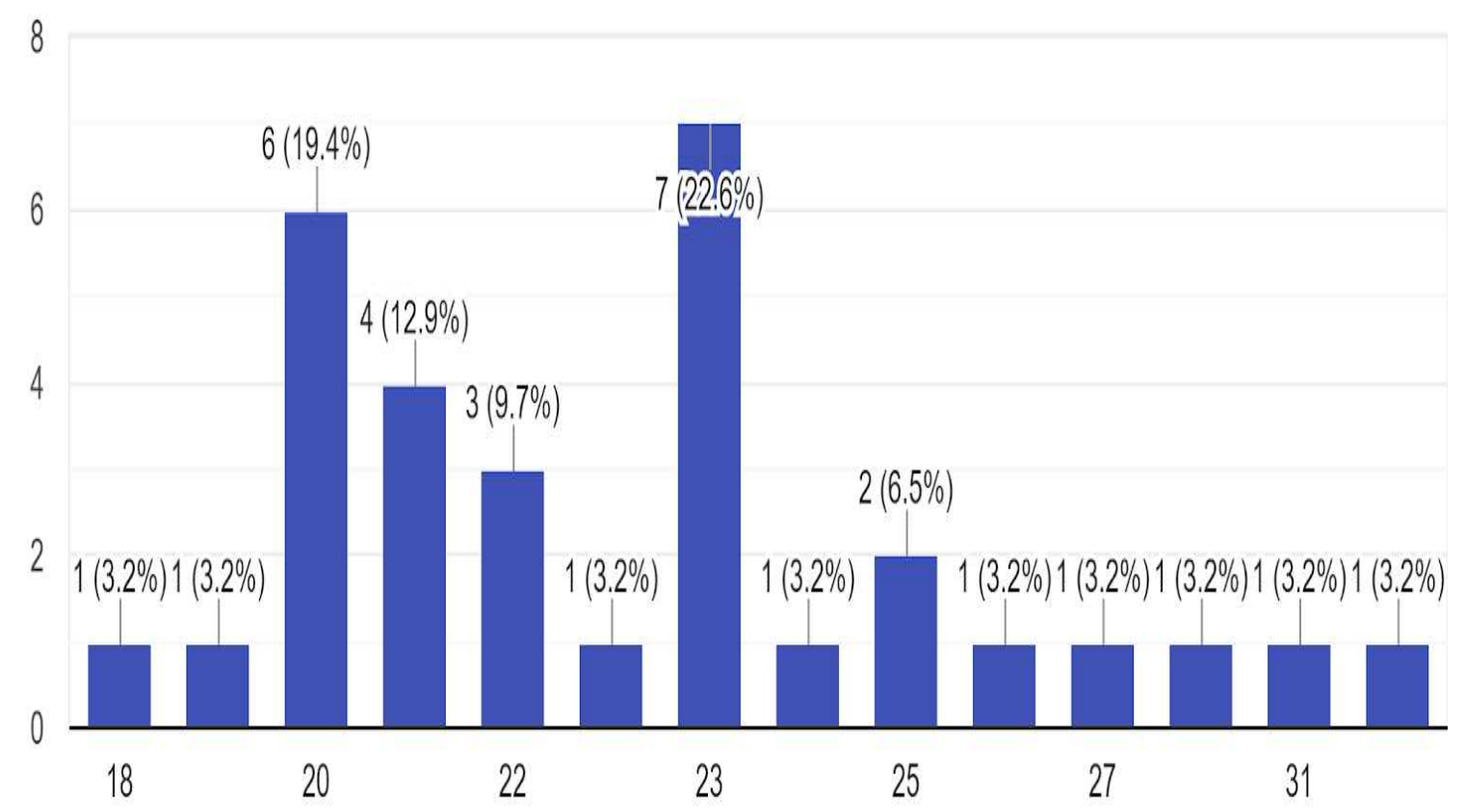

Fig.3. The following chart represents the age distribution of participants. The $\mathrm{X}$-axis is for age and $\mathrm{Y}$-axis denotes the number of responses.
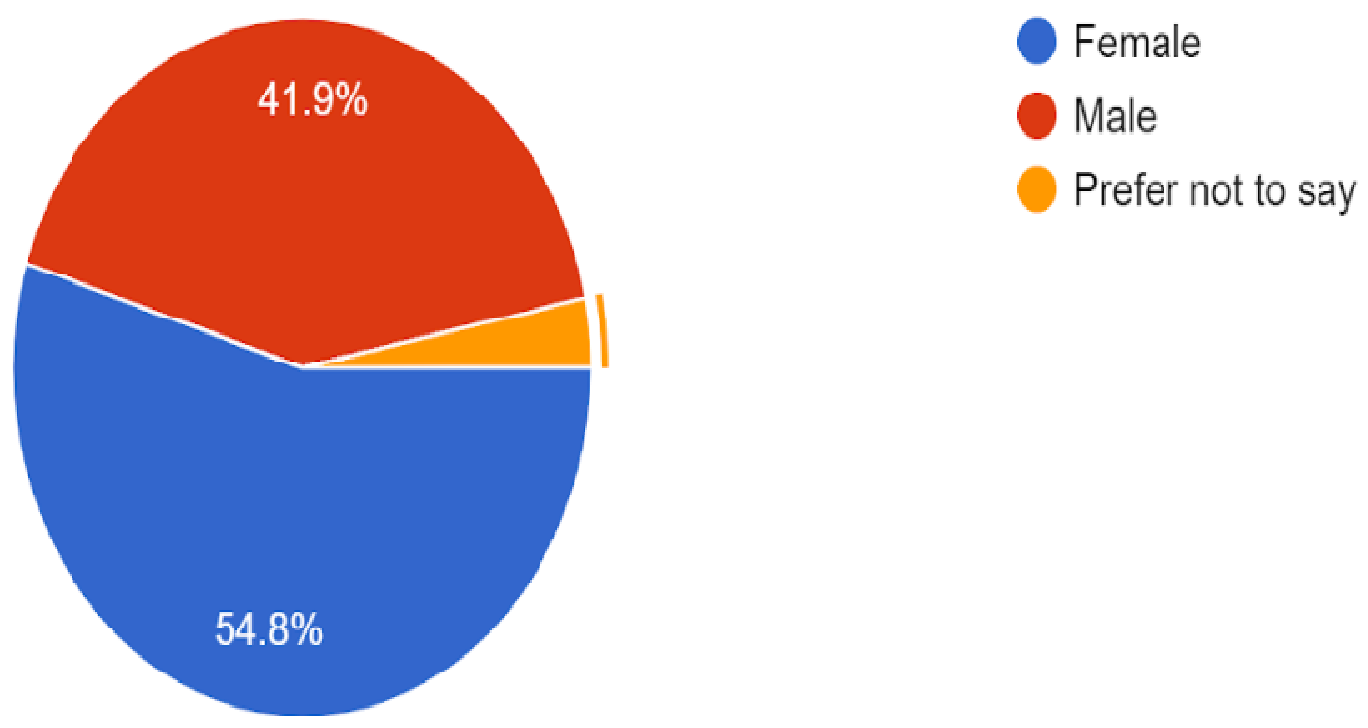

Fig.4. The chart represents the gender ratio of the participants. 

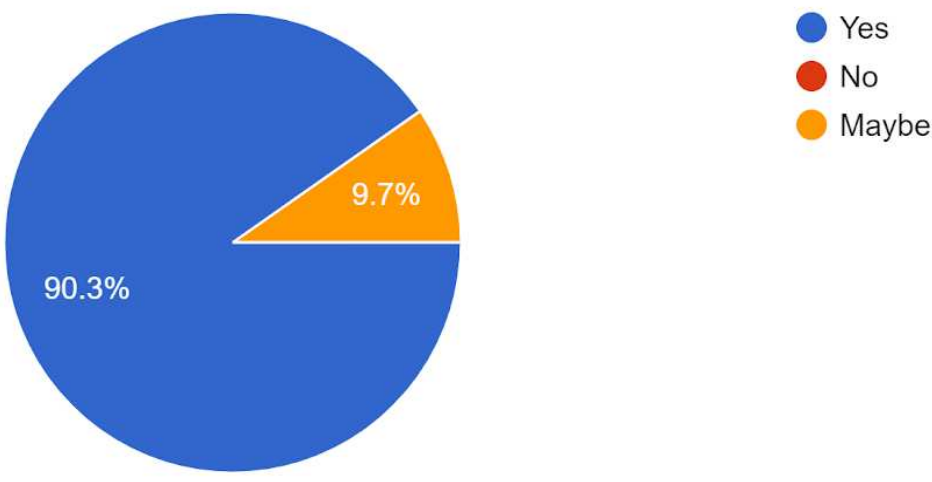

Fig.5. The following chart represents how much people are concerned about climate change's impact on health. The data shows that about $90.3 \%$ are very concerned but $9.7 \%$ are not sure.
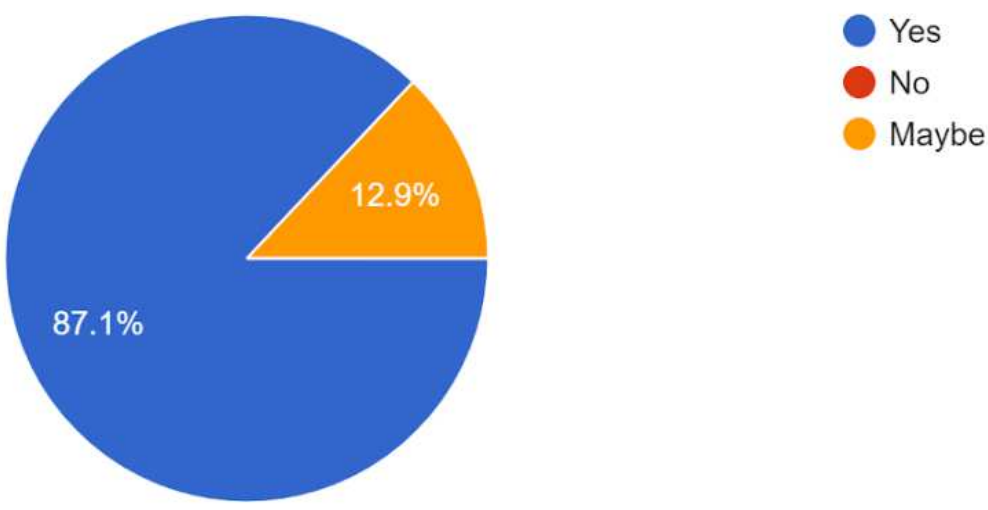

Fig.6: The Chart represents that how much people know that climate change can cause cancer. The data shows about $12.9 \%$ of the total participants are not sure.

\section{CONCLUSIONS AND FUTURE INSIGHTS:}

Still, now we have discussed the impact of climate change on cancer. Now here we should focus on the limitation in this field for the betterment. Data shows that still now peoples are not concerned about the effects of climate change and its impact on cancer so more awareness is required both at the public and academic level. Several projects, camps, internships must be included at the school and college level to improve the knowledge in this field. It will also help to contribute to the students for the betterment of the environment and reduced its risks.
For controlling several consequences of climate change, several steps have been implicated globally but more preparedness and attentiveness are reasonable. Like as for reducing air pollution (majorly contributed to lung cancer) smart policies like low or zeroemission stove ${ }^{25}$ must be used. The steps are reasonable in the case of developing and lowincome countries.

To date, no studies have estimated the carbon footprint of cancer care ${ }^{7}$, so more research must be performed for a better knowledge, and better controlling this both from hospitals and pharmaceutical companies. The work is very important for developed and 
high-income counties. As we know that the health care system of cancer also responsible for a great number of greenhouse emissions starting from the energy, pharmaceutical, medical devices, etc., so more development and policies are very meaningful here to control greenhouse emission. A very effective rule is thus expected to implements in this regard near future. There is a need to assess weaknesses and categorize cost-effective interposition ${ }^{1}$ options in both health and other sector related to health issues because early planning and detections can help reduce future adverse health impacts. Lastly, we should know that peoples don't do what they say, so we should focus on doing something rather saying lots of things.

In conclusion, we can say that climate change positively contributes to cancer development so everybody should be aware of its consequences. I have pointed out some of the limitations but more are there that needs to be assessed by the governing authority in each country and should be controlled by the implementation of some policies.

Availability of data and materials:

All data generated or analyzed during this study are included in this article.

\section{Declaration:}

The author declares that; this work is original \& done by him. Use or Modification of other's articles (open access) data, idea, and information related to this field done after giving appropriate credit to the original author(s) and the source. The author, furthermore, makes no representations that the data available in the referenced papers is free from error.

\section{ACKNOWLEDGEMENT:}

The abstract of this manuscript was accepted at the 2020 GW4 Symposium Climate Change - Science \& Society for oral presentation in 2020. I am thankful to my parents. I would like to thank you all the participants for giving their valuable response in my Survey. I am sorry if I did not cite your valuable paper due to a space issue.

Authors' Contributions: The idea of this work came from PC; he designed the work and performed the survey online. $\mathrm{He}$ independently prepared the manuscript and did reference. The schematics are used here created by PC by using Microsoft PowerPoint.

\section{ETHICS DECLARATIONS}

Ethical approval and consent to participate: All participant's consent had been obtained at the beginning of the online Google form. They all were aware of their contribution.

Competing interests: The author(s) have declared they have no conflict of interest about this content

\section{REFERENCES:}

1. Haines A, Kovats RS, Campbelllendrum D, Corvalan C. Climate change and human health: Impacts, vulnerability and public health. 2006: 585-596. doi:10.1016/j.puhe.2006.01. 002

2. Wright CY, Norval M, Kapwata T, et al. The Incidence of Skin Cancer in Relation to Climate Change in South Africa. :1-11.

3. Asia S, World TS, Assembly H, States M, Region TSEA, Meeting T. Climate Change, and Health. 2008;2.

4. Kaffenberger BH, Shetlar D, Mph SN, Rosenbach M. The effect of climate change on skin disease in North America. J Am Dermatology. 2016. doi:10.1016/j.jaad.2016.08.014

5. Bharath AK. Impact of climate change on skin. 2009:215-218. doi:10.1258/jrsm.2009.080261

6. https://www.hsph.harvard.edu/cchange/news/climate-change-andcancer/.

7. Nogueira LM. Climate Change and Cancer. 2020; 70(4) :239-244. doi:10.3322/caac. 21610

8. Johnson H, Kovats RS, McGregor GR et al. The impact of the 2003 heatwave 
on mortality and hospital admissions in England. Heal Stat Q. 2005:6-11.

9. Giang, P. N., Dung, d., Bao Giang, K., Vinhc, H. V., \& Rocklöv J. The effect of temperature on cardiovascular disease hospital admissions among elderly people in Thai Nguyen Province, Vietnam. Glob Health Action. 2014;(7):23649.

10. Ahern M, Kovats RS, Wilkinson P, Few R MF. Global health impacts of floods: epidemiologic evidence. Epidemiol Rev. 2005:36-46.

11. Albering HJ, van Leusen SM, Moonen EJC HJ, JCS K. Human health risk assessment: a case study involving heavy metal soil contamination after the flooding of the river Meuse during the winter of 1993-1994. Env Heal Perspect. 1999:37-43.

12. Meusel D KWL learned from the 2002 flood in, Dresden, German.In: Menne B, Bertollini R, Kirch $\mathrm{W}$ editors. Extreme weather events and public health response. Berlin. Springer. 2005:175-84.

13. Kovats S, Bouma MJ, Hajat S, Worrell E HA. El Nino and health. Lancet. 2003:1481-1489.

14. International Agency for Research on Cancer. Polychlorinated Dibenzo-paraDioxins and polychlorinated dibenzofurans. IARC Monographs on the Evaluation of Carcinogenic Risks to Humans, No. 69. World Health Organization/International Agency for Research on. World Heal Organ Agency Res Cancer;. 2020. iarc.fr/87.

15. Liu JC, Mickley LJ, Sulprizio MP et al. Particulate air pollution from wildfires in the Western US under climate change. Clim Chang. 2016;(138):655666.

16. Jaffe D, Hafner W, Chand D WA, D. S. Interannual variations in PM2.5 due to wildfires in the Western United States.
2008;(42):2812-2818.

17. Battilani P, Toscano P V der F-K, HJ et al. Aflatoxin B1 contamination in maize in Europe increases due to climate change. Sci Rep. 2016;6:24328.

18. A.A. Motalebi, K. Ardalani and S. Jamili. Effect of Temperature on the Produced Aflatoxins in the Rainbow Trout Feed in West Azerbaijan Province. J Fish Aquat Sci. 2008;3(6):pp392-397.

19. Diffey B. Climate change, ozone depletion and the impact on ultraviolet exposure of human skin. Phys Med Biol. 2004;49:R1-R11.

20. Narayanan, D.L.; Saladi, R.N.; Fox JL. Ultraviolet radiation and skin cancer. Int J Dermatol. 2010;49:978-986.

21. Corona R, Dogliotti E, D'Errico M et al. Risk factors for basal cell carcinoma in a Mediterranean population: role of recreational sun exposure early in life. Arch Derm. 2001;137:1162-1168.

22. Ziegler A, Jonason AS, Leffell DJ et al. Sunburn and p53 in the onset of skin cancer. Nature. 1994;372:773-776.

23. Mancebo, S.E.; Wand SQ. Recognizing the impact of ambient air pollution on skin health. J Eur Acad Dermatol Venereol. 2015;29:2326-2332.

24. Zegarska, B.; Pietkun, K.; GiemzaKucharska, P.; Zegarski, T.; Nowacki, M.S.; Romanska-Gocka K. Changes in Langerhans cells during skin ageing. Postep Dermatol Alergol. 2017;34:260267.

25. $\mathrm{Ku} \mathrm{N}$. Commentary: Abating climate change and lung cancer! 2011;(March):729-730. doi:10.1093/ije/dyr037

26. Hopkinson NS, Hart N, Jenkins G, et al. Climate change and lung health: the challenge for a new president. 1985:295-296. doi:10.1136/thoraxjnl2017-209978

27. Zhang JJ SK. Household air pollution 
from coal and biomass fuels in China: measurements, health impacts, and interventions. Env Heal Perspect. 2007;115:8848-8855.

28. Torres-Duque C, Maldonado D, PerezPadilla R EM, G. V. Biomass fuels and respiratory diseases: a review of the evidence. Proc Am Thorac Soc. 2008;5:577-590.

29. Kurmi OP, Semple S, Simkhada P, Smith WC AJ. COPD and chronic bronchitis risk of indoor air pollution from solid fuel: a systematic review and meta-analysis. Thorax. 2010;65:221228.

30. Lan Q, Chapman RS, Schreinemachers DM, Tian L HX. Household stove improvement and risk of lung cancer in Xuanwei, China. J Natl Cancer Inst. 2002;94:826-835.

31. https://www.who.int/news-room/factsheets/detail/household-air-pollutionand-health.

32. https://www.india.gov.in/ spotlight/ pradhan- mantri-ujjwalayojana\#tab=tab-1.

33. Man RX, Lack DA, Wyatt CE M V. The effect of natural disasters on cancer care: a systematic review. Lancet Oncol. 2018;19:e482-e499.

34. Nogueira LM, Sahar L EJ, Jemal A YK.
Association between declared hurricane disasters and survival of patients with lung cancer undergoing radiation treatment. JAMA. 2019;322:269-271.

35. FDA UF and DA, Scott NRFC, Gottlieb MD. updates on some ongoing shortages related to IV fluids. US Food and Drug Administration; 2020. fda.gov/news-event s/\%0Apress -annou nceme nts/fda-commi ssion\%0Aer-scott -gottl ieb-md-updat es-someongoi\%0Ang-short ages-relat ed-ivfluids.

36. MacNeill AJ, Lillywhite R BC. The impact of surgery on global climate: a carbon footprinting study of operating theatres in three health systems. Lancet Planet Heal. 2017:e381-e388.

37. Chung JW MD. Estimate of the carbon footprint of the US health care sector. JAMA. JAMA. 2009;302:1970-1972.

38. Demark-Wahnefried W. Cancer survival: time to get moving? Data accumulate suggesting a link between physical activity and cancer survival. $J$ Clin Oncol. 2006;24:3517-3518.

39. Monninkhof EM, Elias SG VF, Al. E. Physical activity and breast cancer: a systematic review. Epidemiology. 2007;18:137-157. 